\title{
Post-chemotherapy serum anti-Müllerian hormone level predicts ovarian function recovery
}

\author{
Hyun-Ah Kim ${ }^{1, *}$, Jihye Choi ${ }^{1, *}$, Chan Sub Park1, Min-Ki Seong1, Sung-Eun Hong ${ }^{2}$, Jae-Sung Kim³, In-Chul Park \\ Jin Kyung Lee ${ }^{4}$ and Woo Chul Noh ${ }^{1}$ on behalf of the ASTRRA trial investigators
}

${ }^{1}$ Department of Surgery, Korea Cancer Center Hospital, Korea Institute of Radiological and Medical Sciences, Seoul, Republic of Korea ${ }^{2}$ Department of Translational Research, Korea Institute of Radiological and Medical Sciences, Seoul, Republic of Korea ${ }^{3}$ Division of Basic Radiation Bioscience, Korea Institute of Radiological and Medical Sciences, Seoul, Republic of Korea ${ }^{4}$ KIRAMS Radiation Biobank, Korea Institute of Radiological and Medical Sciences, Seoul, Republic of Korea

Correspondence should be addressed to W C Noh: nohwoo@kcch.re.kr

*(H-A Kim and J Choi contributed equally to this work)

\begin{abstract}
In the era of precision medicine, the prediction of ovarian function recovery from chemotherapy-induced amenorrhoea using feasible biological markers may be helpful to optimise the treatment strategy for young patients with hormone receptor-positive breast cancer. The purpose of this study was to investigate the accuracy of postchemotherapy biological markers for predicting the recovery of ovarian function in breast cancer patients of the ASTRRA trial, with chemotherapy-induced amenorrhoea. Using data of 82 participants from a single institution in the ASTRRA trial, the postchemotherapy serum levels of the anti-Müllerian hormone (AMH), oestradiol, inhibin $B$ and other clinical factors associated with chemotherapy-induced amenorrhoea were evaluated. Recovery of ovarian function was defined by the resumption of menstruation manifested by vaginal bleeding. Fifty-two patients regained menstruation within 55 months after enrolment. In univariate analysis, $<40$ years of age $(P=0.009)$, oestradiol $\geq 37 \mathrm{pg} / \mathrm{mL}(P=0.003)$ or $\mathrm{AMH} \geq 800 \mathrm{pg} / \mathrm{mL}(P=0.026)$ were associated with recovery of menstruation. On multivariate analysis, oestradiol (hazard ratio: $3.171,95 \% \mathrm{Cl}$ : 1.306-7.699, $P=0.011$ ) and AMH (hazard ratio: $2.853,95 \% \mathrm{Cl}: 1.011-8.046, P=0.048$ ) remained as significant independent predictors for resumption of menstruation.

The diagnostic accuracy of age, oestradiol and $\mathrm{AMH}$ in predicting the resumption of menstruation was $38.3,23.3$ and $86.7 \%$, respectively. In conclusion, post-chemotherapy $\mathrm{AMH}$ level might be a relatively accurate predictor of the recovery of ovarian function, presented by resumption of menstruation in breast cancer patients with chemotherapy-induced amenorrhoea.
\end{abstract}

Key Words

- anti-Müllerian hormone

- breast cancer

- ovarian function reserve

- chemotherapy-induced amenorrhea

- tamoxifen

- goserelin
Endocrine Connections (2018) 7, 949-956

\section{Introduction}

Management of young patients with endocrine-sensitive breast cancer is challenging, due to various treatment regimens that may cause menopausal symptoms or infertility, and most importantly, affect the prognosis of the disease. Occurrence of chemotherapy-induced amenorrhoea further complicates the management of this disease. Most high-risk hormone receptor-positive breast cancer patients are treated with adjuvant chemotherapy, http://www.endocrineconnections.org https://doi.org/10.1530/EC-18-0180 (c) 2018 The authors Published by Bioscientifica Ltd

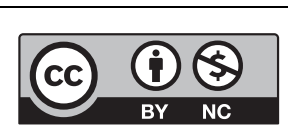

This work is licensed under a Creative Commons Attribution-NonCommercial 4.0 International License. 
and $15-75 \%$ of these patients experience chemotherapyinduced amenorrhoea. Despite this high incidence of chemotherapy-induced amenorrhoea, $27-75 \%$ of patients regain ovarian function $(1,2,3,4,5)$. The selection of optimal adjuvant endocrine therapy for these patients is particularly difficult.

Aromatase inhibitors (AIs) demonstrate superior survival benefit over tamoxifen in postmenopausal patients (6). However, it should be prescribed with caution for patients with uncertain menopausal status, such as patients with chemotherapy-induced amenorrhoea, because AIs may cause a surge in gonadotropin-releasing hormone level and result in unwanted elevated serum oestradiol level (7). Although combining ovarian suppression and AI is a possible treatment option for some patients with chemotherapyinduced amenorrhoea, side effects such as aggravated menopausal symptoms and bone health issues pose a limitation $(8,9)$. Therefore, a reliable and feasible biomarker for predicting ovarian function recovery would help in deciding optimal endocrine therapy strategy for young hormone receptor-positive breast cancer patients with chemotherapy-induced amenorrhoea.

In the evaluation of infertility, anti-Müllerian hormone $(\mathrm{AMH})$, inhibin $\mathrm{B}$, oestradiol, follicularstimulating hormone (FSH) and luteinising hormone have been frequently studied as biomarkers of ovarian function in women treated by chemotherapy (10, 11). Furthermore, it has been suggested that these biomarkers may predict ovarian function recovery in patients preparing for adjuvant endocrine therapy after completion of chemotherapy. A number of studies have reported associations between pre-chemotherapy levels of these biomarkers and resumption of menstruation in breast cancer patients $(1,11,12,13,14,15,16)$. However, data on measurable biomarkers after the completion of chemotherapy in this population have been rarely reported $(17,18,19)$. Post-chemotherapy biomarker levels may reflect changes in the ovarian function differently than biomarker levels measured at the time of diagnosis before undergoing any local or systemic treatment. The biomarkers at the time of diagnosis show an individual's innate follicle reservoir (20); however, post-chemotherapy levels may reflect the actual follicle reserve after gonadotoxic therapy $(21,22,23)$. Therefore, we investigated the accuracy of post-chemotherapy biomarkers to predict ovarian function recovery in patients with chemotherapy-induced amenorrhoea.

\section{Methods}

\section{Study design and patients}

The serum level of post-chemotherapy AMH, inhibin B, FSH and oestradiol were evaluated in the 82 participants of the ASTRRA trial (NCT00912548-clinical trials.gov) who were enrolled at the Korea Cancer Center Hospital. The ASTRRA trial is a randomised, multicentre, phase III trial that evaluated the efficacy of combined ovarian function suppression and tamoxifen vs tamoxifen alone, in hormone receptor-positive breast cancer patients who remain premenopausal after chemotherapy. The trial enrolled premenopausal women $\leq 45$ years of age with hormone receptor-positive breast cancer treated with definitive surgery and chemotherapy. Patients were assigned with one of the following chemotherapy regimens: four cycles of (doxorubicin $60 \mathrm{mg} / \mathrm{m}^{2}$ and cyclophosphamide $600 \mathrm{mg} / \mathrm{m}^{2}$ ) q3w or four cycles of (doxorubicin $60 \mathrm{mg} / \mathrm{m}^{2}$ and cyclophosphamide $600 \mathrm{mg} / \mathrm{m}^{2}$ ) $\mathrm{q} 3 \mathrm{w}$ followed by four cycles of (docetaxel $100 \mathrm{mg} / \mathrm{m}^{2}$ ) q3w or six cycles of (doxorubicin $50 \mathrm{mg} / \mathrm{m}^{2}$ and docetaxel $75 \mathrm{mg} / \mathrm{m}^{2}$ ) q3w. For adjuvant hormone therapy, all patients took tamoxifen regardless of their menstrual status during the study. The study design and enrolment criteria are precisely described in a previous report (24). However, in this study, unlike in the ASTRRA trial, only the presence of vaginal bleeding was accepted as criteria for resumption of ovarian function. Patients who were found to have resumed ovarian function based on FSH levels only without vaginal bleeding were censored at the time of randomisation, as adding ovarian function suppression to these patients could obscure menstruation return. Regaining vaginal bleeding, FSH and oestradiol levels were evaluated within every 6 months of each visit for 5 years and at least yearly thereafter. Blood samples for post-chemotherapy AMH and inhibin B were drawn within 2 months of the final dose of chemotherapy. Consent has been obtained from each patient or subject after full explanation of the purpose and nature of all procedures used. All obtained blood samples were stored in the Korean Institute of Radiological and Medical Sciences (KIRAMS) Radiation Biobank. The study was approved by the institutional review board of the Korea Cancer Center Hospital (IRB No: K-1604-002-035).

\section{Statistical analysis}

The serum levels of post-chemotherapy AMH, oestradiol, inhibin $\mathrm{B}$ and other clinical factors were analysed in

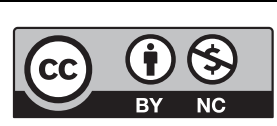

This work is licensed under a Creative Commons Attribution-NonCommercial 4.0 International License. 
relation to ovarian function resumption. The level of serum AMH, oestradiol and inhibin B was evaluated using ELISA. AMH assays were performed using the kit from USCN Life Science, Inc. (Buckingham, UK). AMH values are presented in concentration of $\mathrm{pg} / \mathrm{mL}$. The lower limit of detection was less than $25.4 \mathrm{pg} / \mathrm{mL}$. Inhibin B was quantified using an ELISA kit (BlueGene Biotech Co. Ltd., Shanghai, China) and levels of oestradiol was measured using electro-chemiluminescence immunoassays (Roche Diagnostics). Details of assay procedures are well described in a previous study, in which we successfully estimated the post-chemotherapy levels of the same markers in 32 patients receiving neoadjuvant chemotherapy. The cutoff point of inhibin B ( $\geq 30 \mathrm{pg} / \mathrm{mL})$ was determined based on our previous analysis (25). The cut-off value of $\mathrm{AMH}$ $(\geq 800 \mathrm{pg} / \mathrm{mL}$ ) used in this study, indicative of a functional ovarian reserve, was determined at the level of the lowest $P$ value in the receiver-operating characteristic curve (ROC) analysis. In the ROC analysis of AMH $(\geq 800 \mathrm{pg} / \mathrm{mL})$ for resumption of menstruation, the area under the curve was 0.59 (data not shown). For oestradiol, we used the reference value of $\geq 37 \mathrm{pg} / \mathrm{mL}$ at our institute as a cut-off value for premenopausal women.

The relationships between the levels of biomarkers and clinicopathological parameters were calculated using $\chi^{2}$ test and Student's $t$-test. Kaplan-Meier analysis was performed for each variable to assess the time to ovarian function recovery. Associations between biomarkers of ovarian reserve and resumption of menstruation were evaluated with Cox regression. The accuracy, sensitivity, specificity and positive/negative predictive values were calculated for age, level of oestradiol or level of $\mathrm{AMH}$.

Table 1 Clinicopathological characteristics of the study population.

\begin{tabular}{|c|c|}
\hline Characteristics & Total number of pa \\
\hline \multicolumn{2}{|l|}{ Stage } \\
\hline \multicolumn{2}{|l|}{1} \\
\hline \multicolumn{2}{|l|}{ ॥ } \\
\hline \multicolumn{2}{|l|}{ III } \\
\hline \multicolumn{2}{|l|}{ T stage } \\
\hline \multicolumn{2}{|l|}{$\mathrm{T} 1$} \\
\hline \multicolumn{2}{|l|}{$\mathrm{T} 2$} \\
\hline \multicolumn{2}{|l|}{ T3 } \\
\hline \multicolumn{2}{|l|}{$\mathrm{T} 4$} \\
\hline \multicolumn{2}{|l|}{$\mathrm{N}$ stage } \\
\hline \multicolumn{2}{|l|}{ NO } \\
\hline \multicolumn{2}{|l|}{ N1 } \\
\hline \multicolumn{2}{|l|}{ N2 } \\
\hline \multicolumn{2}{|l|}{ N3 } \\
\hline \multicolumn{2}{|l|}{ Histology } \\
\hline \multirow{2}{*}{\multicolumn{2}{|c|}{$\begin{array}{l}\text { Invasive ductal carcinoma } \\
\text { Invasive lobular carcinoma }\end{array}$}} \\
\hline & \\
\hline \multicolumn{2}{|l|}{ Histologic grade } \\
\hline \multicolumn{2}{|l|}{ G1 } \\
\hline \multicolumn{2}{|l|}{$\mathrm{G} 2$} \\
\hline \multicolumn{2}{|l|}{ G3 } \\
\hline \multicolumn{2}{|l|}{ Unidentified } \\
\hline \multicolumn{2}{|l|}{ Chemotherapy regimen } \\
\hline \multicolumn{2}{|l|}{ Anthracycline + cyclophosphamide } \\
\hline \multicolumn{2}{|l|}{ Anthracycline + cyclophosphamide followed by taxane } \\
\hline \multicolumn{2}{|l|}{ Anthracycline + taxane (to be continued) } \\
\hline \multicolumn{2}{|l|}{ Operation } \\
\hline \multicolumn{2}{|l|}{ Total mastectomy } \\
\hline \multicolumn{2}{|l|}{ Breast conserving surgery } \\
\hline \multicolumn{2}{|l|}{ BMI } \\
\hline \multicolumn{2}{|l|}{$<27$} \\
\hline$\geq 27$ & \\
\hline ASTRRA trial group & \\
\hline Menopause for 2 years, tamoxifen only & \\
\hline Ovarian function resumption, tamoxifen only & \\
\hline $\begin{array}{l}\text { Ovarian function resumption, tamoxifen combining ovarian function suppression by } \\
\text { GnRH agonist }\end{array}$ & \\
\hline
\end{tabular}

GnRH agonist, gonadotropin-releasing hormone agonist.

$$
\begin{array}{lr}
\text { http://www.endocrineconnections.org } & \text { () } 2018 \text { The authors } \\
\text { https://doi.org/10.1530/EC-18-0180 } & \text { Published by Bioscientifica Ltd }
\end{array}
$$

(1)




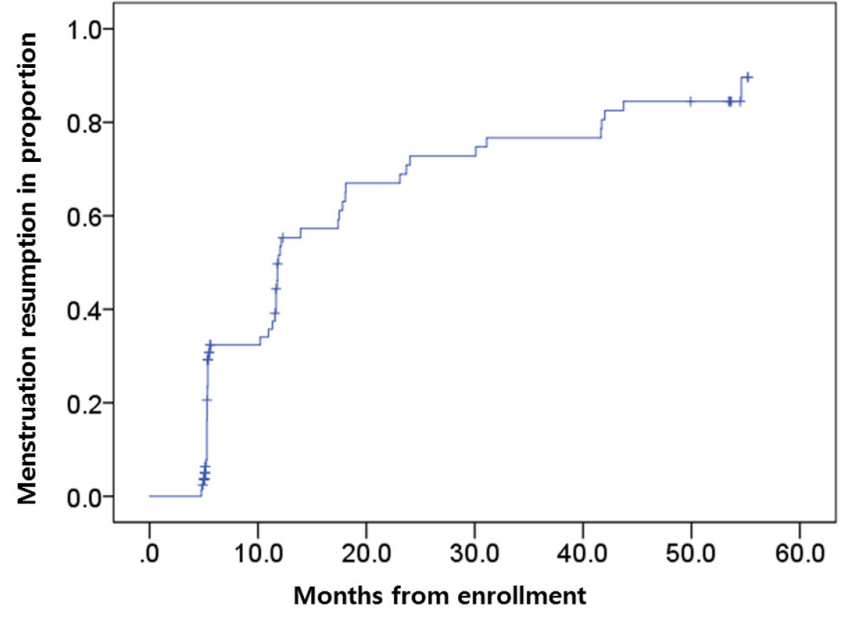

Figure 1

Kaplan-Meier curves of time to ovarian function recovery after chemotherapy. Within the first 2 years after enrolment, resumption of menstruation occurred in 44 patients. After 55 months, however, menstruation recovery was detected in 52 patients.

Values of $P<0.05$ were considered statistically significant. All analyses were performed using the SPSS version 23.0 statistical software package (IBM).

\section{Results}

\section{Patient characteristics and resumption of menstruation}

Median follow-up period was 61.8 months (range 9.1-71.5). Table 1 depicts clinic-pathologic characteristics of the 82 patients. Mean age of the patients at the time of enrolment was $40.8 \pm 3.8$ years (95 percentiles of age, 34-45). Among 82 patients, 24 patients presented with advanced disease. Node positivity was reported in 39 patients. Approximately half of the patients
(42 patients) had been treated with 4 cycles of doxorubicin and cyclophosphamide. Thirteen patients received six cycles of doxorubicin and docetaxel combination without cyclophosphamide.

Resumption of menstruation was detected in 44 patients within the first 2 years after enrolment. However, 52 patients resumed menstruation after 55 months of the follow-up period (Fig. 1).

\section{Predictive values for regaining vaginal bleeding}

In univariate analysis, age $<40$ years $(P=0.009)$, oestradiol $\geq 37 \mathrm{pg} / \mathrm{mL} \quad(P=0.003)$ and $\mathrm{AMH} \geq 800 \mathrm{pg} / \mathrm{mL} \quad(P=0.026)$ were statistically significant in predicting menstruation resumption. However, BMI $\geq 27 \mathrm{~kg} / \mathrm{m}^{2}$, inhibin $\mathrm{B}$ $\geq 30 \mathrm{pg} / \mathrm{mL}$ and types of chemotherapy regimen showed no association with the prediction of menstruation resumption (Table 2 ).

For the multivariate analysis, only those factors that were significant in the univariate analysis were included. Oestradiol (HR: 3.2, 95\% CI: 1.306-7.699, $P=0.011$ ) and AMH (HR: 2.9, 95\% CI: 1.011-8.406, $P=0.048$ ) were regarded as independent predictive markers for menstruation resumption (Table 3).

\section{Diagnostic accuracy of biomarkers for regaining vaginal bleeding}

Table 4 summarises the diagnostic ability of age, oestradiol, and $\mathrm{AMH}$ in predicting the recovery of ovarian function. Among 82 patients initially eligible for the study, 22 patients were censored who had been randomised based on FSH levels only and did not have vaginal bleeding. Therefore, 60 patients were analysed in this study. Age dichotomised at 40 years had a sensitivity of $30.8 \%$,

Table 2 Univariate analysis of predictive values for resumption of menstruation.

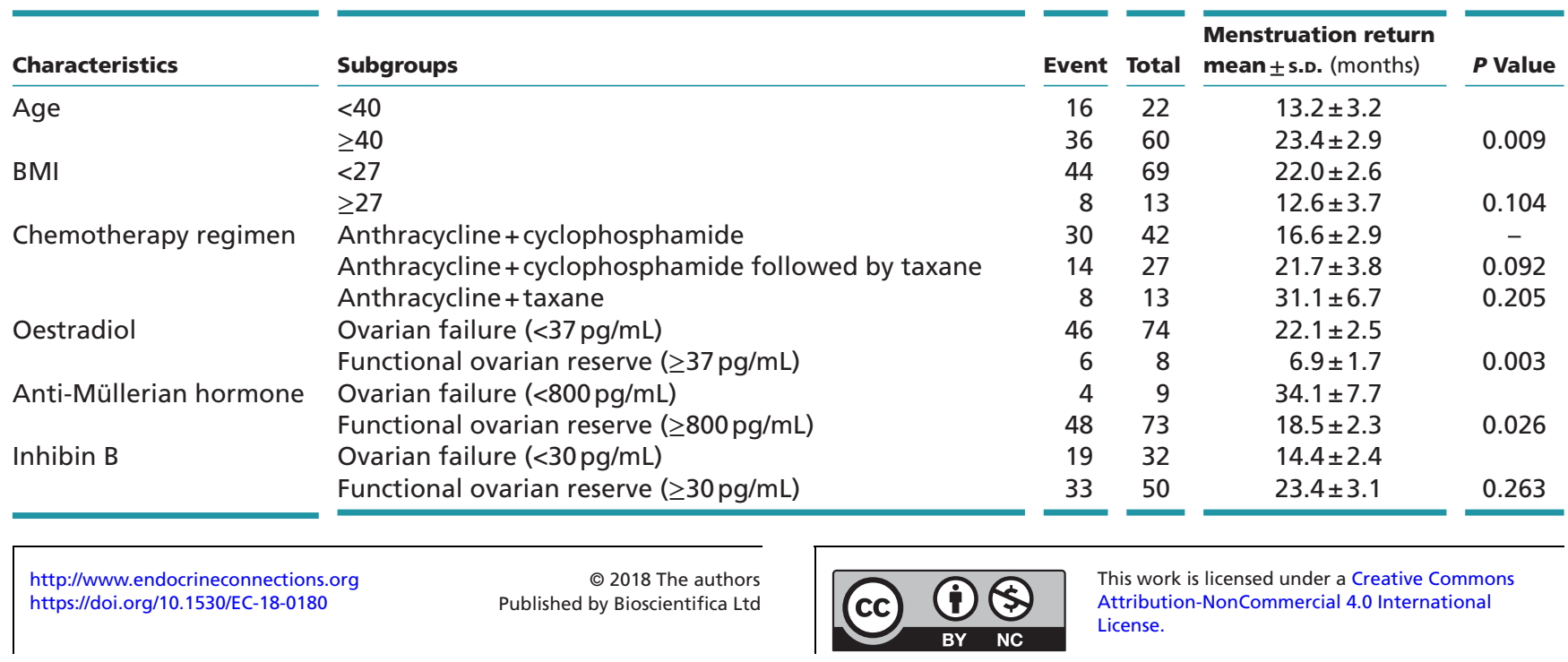


Table 3 Multivariate analysis for predictive values for resumption of menstruation.

\begin{tabular}{l} 
Characteristics \\
\hline Age (years) \\
Oestradiol (pg/mL) \\
Anti-Müllerian hormone $(\mathrm{pg} / \mathrm{mL})$
\end{tabular}

\begin{tabular}{c} 
Subgroups \\
\hline$<40$ vs $\geq 40$ \\
$\geq 37$ vs $<37$ \\
$\geq 800$ vs $<800$ \\
\hline
\end{tabular}

\begin{tabular}{c}
\hline Hazard ratio \\
\hline 1.702 \\
3.171 \\
2.853
\end{tabular}

\begin{tabular}{c}
\hline $\mathbf{9 5 \%} \mathbf{C l}$ \\
\hline $0.883-3.280$ \\
$1.306-7.699$ \\
$1.011-8.046$
\end{tabular}

\begin{tabular}{c}
\hline $\boldsymbol{P}$ Value \\
\hline 0.112 \\
0.011 \\
0.048
\end{tabular}

a specificity of $87.5 \%$ and an accuracy of $38.3 \%(P=0.420)$ in predicting menstrual recovery. Oestradiol had a sensitivity of $11.5 \%$, specificity and positive predictive value of $100 \%$, yet an accuracy of $23.3 \%(P=0.585)$. AMH had a sensitivity of $92.3 \%$, a specificity of $50.0 \%$, positive predictive value of $92.3 \%$ and an accuracy of $86.7 \%$. Overall, AMH was significantly more accurate than age and oestradiol in predicting restoration of ovarian function $(P=0.008)$.

\section{Discussion}

In this study, we investigated the accuracy of postchemotherapy biological markers for predicting the recovery of ovarian function in breast cancer patients. Post-chemotherapy AMH level was identified as an independent predictive marker for ovarian function recovery in patients with chemotherapy-induced amenorrhoea; the accuracy, sensitivity and positive predictive value at 5 years were 86.7, 92.3 and 92.3\%, respectively. Our results add to the existing studies supporting the value of post-chemotherapy AMH level in predicting ovarian function resumption. The strength of our study is that the findings provide a prognostic value of late ovarian function recovery. Repeated prospective and regular evaluation of ovarian function was done through a relatively long follow-up period of 55 months.
This is especially important for selecting optimal adjuvant endocrine therapy in hormone-sensitive premenopausal breast cancer patients, as the therapy may be administered for more than 5 years. In addition, according to the results of our study, AMH proved to be more accurate than the conventional markers in these patients. The level of FSH and E2 may vary depending on the use of adjuvant tamoxifen through a mechanism not clearly understood $(26,27,28)$. Nevertheless, FSH and oestradiol are the only authorised biomarkers currently utilised in the clinic.

In earlier studies, there were inconsistent findings regarding the predictive value of post-chemotherapy AMH level. Discordant with our study is a study that reported post-chemotherapy $\mathrm{AMH}$ as not useful for predicting ovarian function recovery in 59 patients on AI (4). However, in our opinion, the major contribution to this difference between findings was low, undetectable levels of $\mathrm{AMH}$ caused by inclusion of older patients (median age 50.3 years) in the previously mentioned study, as AMH levels naturally decline with the ageing process $(29,30)$. In contrast, by using more sensitive assays, recent studies were successful in providing the predictive value of AMH level. In a study by Chai et al., levels of AMH measured at 2 years after diagnosis had a sensitivity of $96 \%$ in predicting menstruation for the subsequent 3 years (31). In another study by Anderson et al., a sensitivity of $84 \%$ was reported for AMH level at the end of chemotherapy to predict premature ovarian

Table 4 Diagnostic accuracy of predictive measures for resumption of menstruation $(N=60)$.

\begin{tabular}{|c|c|c|c|c|c|}
\hline \multirow[b]{2}{*}{ Characteristics } & \multirow[b]{2}{*}{ Subgroups } & \multicolumn{2}{|c|}{ Menstruation return for 5 years } & \multirow[b]{2}{*}{$P$ value } & \multirow[b]{2}{*}{ Diagnostic accuracy } \\
\hline & & Yes & No & & \\
\hline Age (years) & $\begin{array}{l}<40 \\
\geq 40\end{array}$ & $\begin{array}{l}16 \\
36\end{array}$ & $\begin{array}{l}1 \\
7\end{array}$ & 0.420 & $\begin{array}{l}\text { Sensitivity }=30.8 \% \\
\text { Specificity }=87.5 \% \\
\text { Positive predictive value }=94.1 \% \\
\text { Negative predictive value }=16.2 \% \\
\text { Diagnostic accuracy }=38.3 \%\end{array}$ \\
\hline Oestradiol (pg/mL) & $\begin{array}{l}\geq 37 \\
<37\end{array}$ & $\begin{array}{r}6 \\
46\end{array}$ & $\begin{array}{l}0 \\
8\end{array}$ & 0.585 & $\begin{array}{l}\text { Sensitivity }=11.5 \% \\
\text { Specificity }=100.0 \% \\
\text { Positive predictive value }=100.0 \% \\
\text { Negative predictive value }=14.8 \% \\
\text { Diagnostic accuracy }=23.3 \%\end{array}$ \\
\hline Anti-Müllerian hormone (pg/mL) & $\begin{array}{l}\geq 800 \\
<800\end{array}$ & $\begin{array}{r}48 \\
4\end{array}$ & $\begin{array}{c}4 \\
4\end{array}$ & 0.008 & $\begin{array}{l}\text { Sensitivity }=92.3 \% \\
\text { Specificity }=50.0 \% \\
\text { Positive predictive value }=92.3 \% \\
\text { Negative predictive value }=50.0 \% \\
\text { Diagnostic accuracy }=86.7 \%\end{array}$ \\
\hline $\begin{array}{l}\text { http://www.endocrineconnections.org } \\
\text { https://doi.org/10.1530/EC-18-0180 }\end{array}$ & Publish & $\begin{array}{l}\text { ○ } 2018 \text { The authors } \\
\text { d by Bioscientifica Ltd }\end{array}$ & & & $\begin{array}{l}\text { his work is licensed under a Creative Commons } \\
\text { tttribution-NonCommercial } 4.0 \text { International } \\
\text { icense. }\end{array}$ \\
\hline
\end{tabular}


insufficiency at 2 years (32). However, only a few studies have measured ovarian function at 5 years after diagnosis (33); most studies have less than 2 years of follow-up $(15,18,34,35,36)$, but ovarian function can be recovered 3 years after treatment (37).

The ovarian recovery rate in this study was relatively higher than those reported previously $(1,4)$. Patient homogeneity conferred by the strict enrolment criteria of the ASTRRA trial may have substantially contributed to this result. Participants were relatively younger ( $<45$ years) and those who used CMF regimens were excluded.

In our study, high BMI, levels of inhibin B and types of chemotherapy were not associated with menstruation resumption. Age cut-off at 40 years has been a classical predictor in many studies $(11,38)$. However, in our study, the age at prediction of menstruation resumption was validated in univariate analysis only $(P=0.009)$. This might be explained by the requirement for all patients enrolled at ASTRRA to be $\leq 45$ years. According to a recent meta-analysis, younger age ( $<40$ years) was significant for menstrual recovery, while the use of taxanes resulted in reduced recovery (OR: 0.488, 95\% CI: 0.299-0.796) (39). Controversies exist regarding the role of obesity. It has been shown that obesity was more likely to predict earlier recovery of ovarian function (11); however, other studies, including ours, did not find this in their results (3). This might be caused by the relatively slender statures of Asian patients. Severely obese patients rarely report to the clinic, and this may have influenced statistics.

The cut-off value of $800 \mathrm{pg} / \mathrm{mL}(0.8 \mathrm{ng} / \mathrm{mL})$ for $\mathrm{AMH}$ level at 2 months post-chemotherapy in our study seems somewhat higher than those in recent studies, which ranged between $0.07 \mathrm{ng} / \mathrm{mL}$ and $0.1 \mathrm{ng} / \mathrm{mL}$ depending on the post-treatment time of evaluation $(17,18,19)$. As there are no international standards guiding numerous assay tools and serum AMH levels, careful interpretation is required (40). Post-chemotherapy $\mathrm{AMH}$, in particular, is an area under active research and no optimal cut-off value has been established; thus, further validation is required. As levels of AMH may vary depending on the time of sampling, types of chemotherapy regimen, and age of the study group, there is a possibility for higher cut-off values. In our previous study, post-chemotherapy AMH levels at 2 months after neoadjuvant chemotherapy in women with a median age of 41.5 years ranged between 0.8 and $2.8 \mathrm{ng} / \mathrm{mL}$ (median, $1.0 \mathrm{ng} / \mathrm{mL}$ ), and the cut-off value of $\geq 1000 \mathrm{pg} / \mathrm{mL}$ significantly predicted poorer outcomes in these patients (25). In addition, patients included in the aforementioned studies $(17,18,19)$ had received three cycles of fluorouracil, epirubicin and cyclophosphamide followed by three cycles of docetaxel, some with additional gemcitabine; this adds up to more than six cycles of gonadotoxic therapy. In contrast, more than half of the patients in our study received four cycles of doxorubicin and cyclophosphamide. Six cycles of doxorubicin and docetaxel (without cyclophosphamide, which is highly ovary-toxic) were given to approximately one sixth (13 of 82) of the patients. Thus, less intense treatment regimens for the patients in this study may have contributed to the higher levels of $\mathrm{AMH}$. We hope that the results of our study may help to provide a basis for establishing a generally accepted level for post-chemotherapy AMH.

The limitation of this study is that the entire cohort of the ASTRRA trial was not analysed. This study focused on one institute among the 36 ASTRRA trial institutes. Additionally, we could not obtain pre-treatment levels of $\mathrm{AMH}$, which may have been useful for comparison.

In conclusion, post-chemotherapy $\mathrm{AMH}$ level in patients with chemotherapy-induced amenorrhoea could be an accurate predictive marker for the recovery of ovarian function, manifested by resumption of menstruation. This may have implications for the treatment of young breast cancer patients and decision for further adjuvant endocrine therapy. In future studies, after the survival analysis of ASTRRA trial is announced, we anticipate exploring the relationships between the survival outcome and level of $\mathrm{AMH}$.

\section{Declaration of interest}

The authors declare that there is no conflict of interest that could be perceived as prejudicing the impartiality of the research reported.

\section{Funding}

This study was supported by a grant of the Korea Institute of Radiological and Medical Science (KIRAMS), funded by Ministry of Science, ICT and Future Planning, Republic of Korea (No. 50472-2018).

\section{Acknowledgements}

The authors are sincerely grateful to all of the participants and their families, and to the investigators of the ASTRRA trial. The blood specimens used for this study were distributed by the Korea Institute of Radiological and Medical Sciences (KIRAMS) Radiation Biobank (KRB02016-I002).

\section{References \\ 1 Smith IE, Dowsett M, Yap YS, Walsh G, Lonning PE, Santen RJ \& Hayes D. Adjuvant aromatase inhibitors for early breast cancer after chemotherapy-induced amenorrhoea: caution and suggested guidelines. Journal of Clinical Oncology 200624 2444-2447. (https:// doi.org/10.1200/JCO.2005.05.3694) \\ 2 Yu B, Douglas N, Ferin MJ, Nakhuda GS, Crew K, Lobo RA $\&$ Hershman DL. Changes in markers of ovarian reserve and}

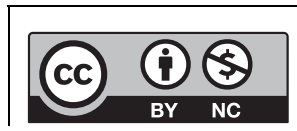

This work is licensed under a Creative Commons Attribution-NonCommercial 4.0 International License. 
endocrine function in young women with breast cancer undergoing adjuvant chemotherapy. Cancer 2010116 2099-2105. (https://doi. org/10.1002/cncr.25037)

3 Henry NL, Xia R, Banerjee M, Gersch C, McConnell D, Giacherio D, Schott AF, Pearlman M, Stearns V, Partridge AH, et al. Predictors of recovery of ovarian function during aromatase inhibitor therapy. Annals of Oncology 201324 2011-2016. (https://doi.org/10.1093/ annonc/mdt149)

4 Henry NL, Xia R, Schott AF, McConnell D, Banerjee M \& Hayes DF. Prediction of postchemotherapy ovarian function using markers of ovarian reserve. Oncologist 201419 68-74. (https://doi.org/10.1634/ theoncologist.2013-0145)

5 Ruddy KJ, O'Neill A, Miller KD, Schneider BP, Baker E, Sparano JA, Dang C, Northfelt DW, Sledge GW Jr \& Partridge AH. Biomarker prediction of chemotherapy-related amenorrhea in premenopausal women with breast cancer participating in E5103. Breast Cancer Research and Treatment 2014144 591-597. (https://doi.org/10.1007/ s10549-014-2891-0)

6 Burstein HJ, Griggs JJ, Prestrud AA \& Temin S. American Society of Clinical Oncology Clinical Practice guideline update on adjuvant endocrine therapy for women with hormone receptor-positive breast cancer. Journal of Oncology Practice 20106 243-246. (https://doi. org/10.1200/JOP.000082)

7 Guerrero A, Gavila J, Folkerd E, Ortiz B, Martinez F, Garcia A, Climent MA, Guillem V \& Ruiz A. Incidence and predictors of ovarian function recovery (OFR) in breast cancer (BC) patients with chemotherapy-induced amenorrhea (CIA) who switched from tamoxifen to exemestane. Annals of Oncology 201324 674-679. (https://doi.org/10.1093/annonc/mds464)

8 Nystedt M, Berglund G, Bolund C, Fornander T \& Rutqvist LE. Side effects of adjuvant endocrine treatment in premenopausal breast cancer patients: a prospective randomized study. Journal of Clinical Oncology 200321 1836-1844. (https://doi.org/10.1200/ JCO.2003.04.024)

9 Rosendahl M, Andersen CY, la Cour Freiesleben N, Juul A, Lossl K \& Andersen AN. Dynamics and mechanisms of chemotherapyinduced ovarian follicular depletion in women of fertile age. Fertility and Sterility 201094 156-166. (https://doi.org/10.1016/j. fertnstert.2009.02.043)

10 Shuster LT, Rhodes DJ, Gostout BS, Grossardt BR \& Rocca WA. Premature menopause or early menopause: long-term health consequences. Maturitas 201065 161-166. (https://doi.org/10.1016/j. maturitas.2009.08.003)

11 Broer SL, Broekmans FJ, Laven JS \& Fauser BC. Anti-Mullerian hormone: ovarian reserve testing and its potential clinical implications. Human Reproduction Update 201420 688-701. (https:// doi.org/10.1093/humupd/dmu020)

12 Su HC, Haunschild C, Chung K, Komrokian S, Boles S, Sammel MD \& DeMichele A. Prechemotherapy antimullerian hormone, age, and body size predict timing of return of ovarian function in young breast cancer patients. Cancer 2014120 3691-3698. (https://doi. org/10.1002/cncr.28942)

13 Su HI, Sammel MD, Green J, Velders L, Stankiewicz C, Matro J, Freeman EW, Gracia CR \& DeMichele A. Antimullerian hormone and inhibin $\mathrm{B}$ are hormone measures of ovarian function in late reproductive-aged breast cancer survivors. Cancer 2010116 592-599. (https://doi.org/10.1002/cncr.24746)

14 Lutchman Singh K, Muttukrishna S, Stein RC, McGarrigle HH, Patel A, Parikh B, Groome NP, Davies MC \& Chatterjee R. Predictors of ovarian reserve in young women with breast cancer. British Journal of Cancer 200796 1808-1816. (https://doi.org/10.1038/ sj.bjc.6603814)

15 Anders C, Marcom PK, Peterson B, Gu L, Unruhe S, Welch R, Lyons P, Behera M, Copland S, Kimmick G, et al. A pilot study of predictive markers of chemotherapy-related amenorrhea among premenopausal women with early stage breast cancer. Cancer Investigation 200826 286-295. (https://doi.org/10.1080/07357900701829777)

16 Anderson RA \& Cameron DA. Pretreatment serum anti-mullerian hormone predicts long-term ovarian function and bone mass after chemotherapy for early breast cancer. Journal of Clinical Endocrinology and Metabolism 201196 1336-1343. (https://doi.org/10.1210/ jc.2010-2582)

17 Barnabei A, Strigari L, Marchetti P, Sini V, De Vecchis L, Corsello SM $\&$ Torino F. Predicting ovarian activity in women affected by early breast cancer: a meta-analysis-based nomogram. Oncologist 201520 1111-1118. (https://doi.org/10.1634/theoncologist.2015-0183)

18 Decanter C, Cloquet M, Dassonneville A, D'Orazio E, Mailliez A \& Pigny P. Different patterns of ovarian recovery after cancer treatment suggest various individual ovarian susceptibilities to chemotherapy. Reproductive BioMedicine Online 201836 711-718. (https://doi. org/10.1016/j.rbmo.2018.02.004)

19 Dezellus A, Barriere P, Campone M, Lemanski C, Vanlemmens L, Mignot L, Delozier T, Levy C, Bendavid C, Debled M, et al. Prospective evaluation of serum anti-Mullerian hormone dynamics in 250 women of reproductive age treated with chemotherapy for breast cancer. European Journal of Cancer 201779 72-80. (https://doi. org/10.1016/j.ejca.2017.03.035)

20 Trapp E, Steidl J, Rack B, Kupka MS, Andergassen U, Juckstock J, Kurt A, Vilsmaier T, de Gregorio A, de Gregorio N, et al. AntiMullerian hormone (AMH) levels in premenopausal breast cancer patients treated with taxane-based adjuvant chemotherapy - a translational research project of the SUCCESS A study. Breast 201735 130-135. (https://doi.org/10.1016/j.breast.2017.07.007)

21 van Rooij IA, Broekmans FJ, te Velde ER, Fauser BC, Bancsi LF, de Jong FH \& Themmen AP. Serum anti-Mullerian hormone levels: a novel measure of ovarian reserve. Human Reproduction 200217 3065-3071. (https://doi.org/10.1093/humrep/17.12.3065)

22 Anderson RA, Themmen AP, Al-Qahtani A, Groome NP \& Cameron DA. The effects of chemotherapy and long-term gonadotrophin suppression on the ovarian reserve in premenopausal women with breast cancer. Human Reproduction 200621 2583-2592. (https://doi.org/10.1093/humrep/del201)

23 Codacci-Pisanelli G, Del Pup L, Del Grande M \& Peccatori FA. Mechanisms of chemotherapy-induced ovarian damage in breast cancer patients. Critical Reviews in Oncology/Hematology 2017113 90-96. (https://doi.org/10.1016/j.critrevonc.2017.03.009)

24 Kim HA, Ahn SH, Nam SJ, Park S, Ro J, Im SA, Jung YS, Yoon JH, Hur MH, Choi YJ, et al. The role of the addition of ovarian suppression to tamoxifen in young women with hormone-sensitive breast cancer who remain premenopausal or regain menstruation after chemotherapy (ASTRRA): study protocol for a randomized controlled trial and progress. BMC Cancer 201616 319. (https://doi. org/10.1186/s12885-016-2354-6)

25 Kim HA, Seong MK, Kim JH, Kim YG, Choi HS, Kim JS, Park IC, Jin HO, Lee JK \& Noh WC. Prognostic value of anti-mullerian hormone and inhibin B in patients with premenopausal hormone receptor-positive breast cancer. Anticancer Research 201636 1051-1057.

26 Rossi E, Morabito A, Di Rella F, Esposito G, Gravina A, Labonia V, Landi G, Nuzzo F, Pacilio C, De Maio E, et al. Endocrine effects of adjuvant letrozole compared with tamoxifen in hormone-responsive postmenopausal patients with early breast cancer: the HOBOE trial. Journal of Clinical Oncology 200927 3192-3197. (https://doi. org/10.1200/JCO.2008.18.6213)

27 Amir E, Freedman O, Allen L, Colgan T \& Clemons M. Defining ovarian failure in amenorrheic young breast cancer patients. Breast 201019 545-548. (https://doi.org/10.1016/j.breast.2010.06.003)

28 Jung M, Shin HJ, Rha SY, Jeung HC, Hong S, Moon YW, Kim HS, Oh KJ, Yang WI, Roh JK, et al. The clinical outcome of chemotherapy-induced amenorrhea in premenopausal young patients with breast cancer with long-term follow-up. Annals of http://www.endocrineconnections.org https://doi.org/10.1530/EC-18-0180

(C) 2018 The authors Published by Bioscientifica Ltd
This work is licensed under a Creative Commons Attribution-NonCommercial 4.0 International License. 
Surgical Oncology 201017 3259-3268. (https://doi.org/10.1245/ s10434-010-1172-3)

29 Seifer DB, Baker VL \& Leader B. Age-specific serum anti-Mullerian hormone values for 17,120 women presenting to fertility centers within the United States. Fertility and Sterility 201195 747-750. (https://doi.org/10.1016/j.fertnstert.2010.10.011)

30 La Marca A, Grisendi V \& Griesinger G. How much does AMH really vary in normal women? International Journal of Endocrinology 2013 2013959487.

31 Chai J, Howie AF, Cameron DA \& Anderson RA. A highly-sensitive anti-Mullerian hormone assay improves analysis of ovarian function following chemotherapy for early breast cancer. European Journal of Cancer 201450 2367-2374. (https://doi.org/10.1016/j. ejca.2014.06.011)

32 Anderson RA, Mansi J, Coleman RE, Adamson DJA, Leonard RCF. The utility of anti-mullerian hormone in the diagnosis and prediction of loss of ovarian function following chemotherapy for early breast cancer. European Journal of Cancer 201787 58-64. (https://doi. org/10.1016/j.ejca.2017.10.001)

33 Hamy AS, Porcher R, Cuvier C, Giacchetti S, Schlageter MH, Coussieu C, Gronier H, Feugeas JP, Adoui N, Lacorte JM, et al. Ovarian reserve in breast cancer: assessment with anti-Mullerian hormone. Reproductive BioMedicine Online 201429 573-580. (https:// doi.org/10.1016/j.rbmo.2014.07.008)

34 Han HS, Ro J, Lee KS, Nam BH, Seo JA, Lee DH, Lee H, Lee ES, Kang HS \& Kim SW. Analysis of chemotherapy-induced amenorrhea rates by three different anthracycline and taxane containing regimens for early breast cancer. Breast Cancer Research and Treatment 2009115 335-342. (https://doi.org/10.1007/s10549-008-0071-9)
35 Freour T, Barriere P \& Masson D. Anti-mullerian hormone levels and evolution in women of reproductive age with breast cancer treated with chemotherapy. European Journal of Cancer 2017 74 1-8. (https:// doi.org/10.1016/j.ejca.2016.12.008)

36 van Hellemond IEG, Vriens IJH, Peer PGM, Swinkels ACP, Smorenburg CH, Seynaeve CM, van der Sangen MJC, Kroep JR, de Graaf H, Honkoop AH, et al. Ovarian function recovery during anastrozole in breast cancer patients with chemotherapy-induced ovarian function failure. Journal of the National Cancer Institute 2017 109 djx074. (https://doi.org/10.1093/jnci/djx074)

37 Sukumvanich P, Case LD, Van Zee K, Singletary SE, Paskett ED, Petrek JA, Naftalis E \& Naughton MJ. Incidence and time course of bleeding after long-term amenorrhea after breast cancer treatment: a prospective study. Cancer 2010116 3102-3111. (https://doi. org/10.1002/cncr.25106)

38 Meng K, Tian W, Zhou M, Chen H \& Deng Y. Impact of chemotherapy-induced amenorrhea in breast cancer patients: the evaluation of ovarian function by menstrual history and hormonal levels. World Journal of Surgical Oncology 201311 101. (https://doi. org/10.1186/1477-7819-11-101)

39 Silva C, Caramelo O, Almeida-Santos T \& Ribeiro Rama AC. Factors associated with ovarian function recovery after chemotherapy for breast cancer: a systematic review and meta-analysis. Human Reproduction 201631 2737-2749. (https://doi.org/10.1093/humrep/ dew224)

40 Nelson SM \& La Marca A. The journey from the old to the new AMH assay: how to avoid getting lost in the values. Reproductive BioMedicine Online 201123 411-420. (https://doi.org/10.1016/j. rbmo.2011.06.011)

Received in final form 9 July 2018

Accepted 16 July 2018

Accepted Preprint published online 16 July 2018

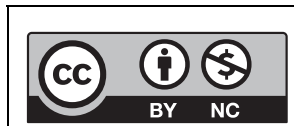

This work is licensed under a Creative Commons Attribution-NonCommercial 4.0 International License. 